12 Johnson MR, Cross M, Cardew SA. Inner city residents, ethnic minorities and primary health care. Postgrad Med J 1983;59:664-7.

13 Modood T. Ethnic minorities in Britain: diversity and disadvantage. London: Policy Studies Institute, 1997

14 Balarajan R, Yuen P, Raleigh VS. Ethnic differences in general practitioner consultations. BMJ 1989;299:958-60.

15 Smaje C, Le Grand J. Ethnicity, equity and the use of health services in the British NHS. Soc Sci Med 1997;45:485-96.

16 Rudat K. Black and minority ethnic groups in England: health and lifestyles. London: Health Education Authority, 1994.

17 Smaje C. Health, race and ethnicity: making sense of the evidence. London: King's Fund Institute, 1995.

18 Foster K, Jackson B, Thomas M, Hunter P, Bennett N. Appendix C. In: General Household Survey 1993. London: HMSO, 1995.
19 Office for Population Censuses and Surveys. 1991 census: children and young adults. Vol 1. London: HMSO, 1994.

20 Macintyre S, Pritchard C. Comparisons between the self assessed and observer-assessed presence and severity of colds. Soc Sci Med 1989;29:1243-8

21 Lundberg O, Manderbacka K. Assessing reliability of self-rated health Scand J Soc Med 1996;24:218-24.

22 Ecob R, Macintyre S, West P. Reporting by parents of longstanding illness in their adolescent children. Soc Sci Med 1993;36:1017-22

23 Norusis MJ. Base system user's guide, release 6.0. Chicago: SPss, 1993.

24 Balarajan R, Raleigh VS, Yuen P. Hospital care among ethnic minorities in Britain. Health Trends 1991;23:90-3.

25 Smaje C. Equity and the ethnic patterning of GP services in Britain. Soc Policy Administration 1998;32:116-31.

(Accepted 10 July 1998)

\title{
Patients' preference for male or female breast surgeons: questionnaire study
}

\author{
Iona Reid
}

Patients' preferences in the provision of health care are an important consideration. Although several studies have investigated patients' preferences for male or female general practitioners, ${ }^{1-3}$ few studies have considered preference for male or female surgeons, and preference of women for male or female breast surgeons has not been reported. Until recently the small numbers of female consultant surgeons in Britain meant that patients did not have a choice of male or female surgeon. This will change, however, with increasing numbers of female consultants and may have implications for the staffing of specialist breast units.

\section{Subjects, methods, and results}

In September 1997 a female consultant surgeon became available at Victoria Infirmary's specialist breast clinic, which had previously been run by a male consultant. From October 1997, 100 consecutive newly referred patients were identified by clinic receptionists on arrival and asked to fill in an anonymous questionnaire. Patients were asked their age and ethnic origin. The questionnaire then gave three options for consultant surgeon-male, female, or no preference-and the patients were asked to state the reason for their preference. Ninety eight completed questionnaires were obtained; two patients declined to complete the questionnaire.

Sixty seven patients $(95 \%$ confidence interval 58 to 75) had no preference for a male or female consultant and 31 (23 to 41) preferred a female consultant. No patient preferred a male consultant. Patients who preferred a female surgeon were younger (median age 35 (range 16-56) years versus 42 (18-83) years for women with no preference; $\mathrm{P}=0.005$, independent $t$ test). Seven $(23 \%)$ women who preferred female surgeons gave their ethnic origin as Asian compared with one $(1 \%)$ woman with no specific preference $(\mathrm{P}=0.003$, Fisher's exact test).

Women who stated a preference for a female surgeon made comments such as "women are easier to talk to" and "I feel less embarrassed with a woman." Patients who had no preference in general felt that a surgeon's sex did not affect competence and that the most important issue was to have a good surgeon irrespective of sex.

\section{Comment}

Previous studies in surgical outpatient clinics and general practice have found that about a third of patients prefer a health professional of their own sex and two thirds have no specific preference. ${ }^{1-3}$ In general surgical clinics, which have roughly equal numbers of male and female patients, this balances out reasonably evenly. At breast clinics almost all the patients are women, and it is not surprising that the results of this study are similar to those of a study of patients' preferences for male or female gynaecologists. ${ }^{4}$

The most striking finding is that none of the women preferred a male surgeon. The United Kingdom has a shortage of female consultant surgeons. In 1996, only 2.3\% of consultants in general surgery in England and Wales were women (Women in Surgical Training, Royal College of Surgeons of England, personal communication). Most specialist breast clinics do not have female consultants, although many have women in junior grades. Twelve per cent of registrars training in general surgery in England and Wales were female in 1996 (Women in Surgical Training, personal communication), and this percentage will probably increase. This study suggests that up to one third of patients may prefer to be referred to a breast clinic with a female consultant. This will be possible only when more female consultants are available.

Funding: None.

Conflict of interest: None

1 Kerssens J, Benzing J, Andela M. Patient preference for genders of health professionals. Soc Sci Med 1997;44:1531-40.

2 Fennema K, Meyer DL, Owen N. Sex of physician: patients' preferences and stereotypes. J Fam Pract 1990;30:441-6.

3 Weyrauch KF, Boiko PE, Alvin B. Patient sex role and preference for a male or female physician. J Fam Pract 1990;30:559-62.

4 Haar E, Halitsky V, Stricker G. Factors related to the preference for a female gynaecologist. Medical Care 1975;13:782-90.

(Accepted 16 July 1998)
University of Glasgow and Victoria Infirmary, Glasgow G42 9TY Iona Reid, senior lecturer in surgery

imreid@msn.com

BMJ 1998;317:1051 